Acta Poetica $33 \cdot 2$

JULIO-DICIEMBRE

$2012(181-208)$

\title{
Naturaleza y origen de los demonios en la épica tibetana de Gesar de Ling
}

\author{
Bertha Aceves
}

El poema épico del héroe tibetano Gesar de Ling nace de tradición oral, posteriormente es escrito en diversas lenguas, y sus interpretaciones orales, en el Tíbet, perduran hasta nuestros días. El conflicto que desata las acciones en el relato es el enfrentamiento del héroe contra los seres demoníacos, que asolan y subyugan al pueblo tibetano. La categoría de demonios en el occidente difiere de la naturaleza de los demonios en el budismo tibetano. La subyugación de los demonios por Gesar de Ling, que se efectúa en el poema, corresponde a uno de los objetivos del budismo a su llegada al Tíbet.

Palabras clave: Gesar de Ling, épica tibetana, demonios.

The epic poem of the Tibetan hero Gesar of Ling is born of oral tradition, then it is written in various languages, and their oral interpretations, in Tibet, persist until our days. The conflict that it unleashes the actions in the story is the confrontation of the hero against the demonic beings, which plague and subjugates the Tibetan people. The categories of demons in the west differ from the nature of the demons in the Tibetan Buddhism. The subjugation of the demons by Gesar of Ling, which is made in the poem, is one of the objectives of Buddhism in its arrival to Tibet.

Keywords: Gesar of Ling, tibetan epic, demons.

Fecha de recepción: 5 de diciembre de 2011

Fecha de aceptación: 11 de junio de 2012 

Bertha Aceves

Instituto de Investigaciones Filológicas

Universidad Nacional Autónoma de México

\section{Naturaleza y origen de los demonios en la épica tibetana de Gesar de Ling}

El rey Gesar de Ling es la figura central de un ciclo de relatos orales del Tíbet, Mongolia, China y otras partes de Asia, que se presenta en varias versiones en tibetano, en mongol y en chino; sin embargo, se sabe que su origen se sitúa en el este o noreste del Tíbet, dado que las escenas del poema se ubican en esas regiones (Francke, xxvii).

Gesar nace, según el poema, para pacificar a los demonios que asolaban al Tíbet; esta actividad se relaciona con un suceso histórico acaecido en esas tierras durante los siglos VII y VIII: el arribo del budismo y el confrontamiento que tuvo con las creencias que dominaban el entorno. ${ }^{1}$ Ahora bien, en la épica de Gesar, como en otros relatos del budismo tibetano, los demonios tienen un origen y una naturaleza muy diversos a los que el occidente cristiano construyó para sus propios demonios. El imaginario de estas dos visiones de la realidad, la budista tibetana y la cristiana occidental, creó una identidad diferente del demonio en cada una de estas culturas.

${ }^{1}$ El rey Songtsen Gampo del Tíbet unifica el país y expande las fronteras (siglo VII). Se casó con dos princesas, una nepalí y otra china, quienes eran budistas e introdujeron el budismo Mahayana al Tíbet. 


\section{El argumento del poema}

En general, casi todas las interpretaciones de esta épica se inician cuando los dioses, consternados porque en la tierra prevalecía el dominio de los Reyes Demonios, deciden enviar a uno de sus hijos para que extermine su poderío. ${ }^{2}$ En los relatos tibetanos, es Padmasambhava ${ }^{3}$ quien le pide a Tubha Gewa, el más joven de los dioses, que renazca en la tierra para que proteja y libere a los seres del imperio de los demonios y restaure el dominio del dharma.

La épica puede dividirse en tres partes: la primera habla del nacimiento de Gesar y de su vida hasta que es proclamado rey; la segunda, el corazón de la épica, narra las varias expediciones y distintas guerras, pequeñas y grandes, que emprende Gesar; y la tercera, la final, describe la pacificación del reino.

El núcleo principal del relato se compone de cuatro cantos, en los que Gesar de Ling se enfrenta a las cuatro Reyes Demonios y los vence. Después de cumplir con su misión, Gesar parte a un escondido reino celeste, del cual regresará en un lejano futuro, para ayudar a los hombres a combatir las fuerzas dañinas.

Aunque el relato esté distribuido en tres partes, las continuas representaciones orales de la gesta han hecho del poema una estructura abierta, de forma tal que, generación tras generación de artistas, de varias regiones y de distintas épocas, han interpretado la épica e insertado pequeños interludios, y así han expandido el corpus oral y escrito de este poema.

We have more than a hundred volumes of written down Gesar epics in Tibetan. There are more than 2100 hours of recoding of Gesar performances archived in Lhasa and Peking. Beyond that there are an as yet

${ }^{2}$ La versión que escribe Alexandra David-Néel es la única traducida al español y la única que incluye un preámbulo que relata por qué se engendran y nacen los Reyes Demonios en el Tíbet; por ello, en ella se sustenta el presente ensayo. Las otras ediciones del poema, casi todas en inglés, pueden consultarse en la bibliografía final.

${ }^{3}$ Padmasambhava (El nacido del loto) es el fundador de la escuela tibetana de budismo Nyingma en el siglo VIII e introductor del budismo tántrico en el Tíbet. Se le conoce más como Guru Rinpoche o el Maestro Precioso. 
uncounted number of liturgies which concern Gesar and his retinue as cult objects. And collateral versions of the Gesar fan out across Central Asia and the Far East (Kornman, 11). ${ }^{4}$

\section{Tentativas de fechar el poema}

Un poema como la épica de Gesar de Ling, cuyo origen fue oral y que a lo largo del tiempo ha tenido distintas interpretaciones, es muy difícil de fijar en el tiempo. Algunos investigadores precisan el inicio del poema entre los siglos x y XI, dado que identifican al héroe épico con un personaje histórico mencionado en una crónica de la dinastía rLangs (Samuel, 174), quien fuera el rey de la provincia de Ling. Sin embargo, en opinión de otros, tenga o no relación el personaje Gesar de Ling con una figura histórica, el inicio del poema puede establecerse en épocas anteriores:

I suggest that even of we accept the existence of an eleventh-century King of tribal chieftain named Ge-sar we cannot take him as the sole origin of the Ge-sar proto-epic. There are many features of the epic that suggest tan any such historical Ge-sar was at most a figure about which other and possibly older stories gradually crystallised (174). ${ }^{5}$

En este mismo sentido, otro estudioso añade:

Furthermore, the epic reflects Tibetan society during the sixth to ninth centuries rather than the tenth century. Thus a satisfactory conclusion

4 "Tenemos más de mil volúmenes escritos en tibetano y hay más de dos mil cien horas de representaciones orales grabadas en Lhasa y Beijing. Además, hay un incontable número de documentos litúrgicos que se relacionan con Gesar y su corte. Y otras versiones colaterales de Gesar que se extienden a lo largo de Asia central y del este cercano" [todas las traducciones de las citas son mías].

5 "Sugiero que, aun si aceptamos la existencia de un rey o un jefe tribal llamado Gesar en el siglo XI, no podemos tomarlo como el único origen de la proto-épica de Gesar. Hay muchas características de la épica que sugieren que ningún Gesar histórico fue la figura de muchas otras historias más antiguas, que gradualmente se cristalizaron”. 
about the epic's origins cannot be drawn based on the lifespans of historical heroic figures (Lianrong, 335). ${ }^{6}$

Tiempo después, los cantos fueron grabados en tablillas de madera y se hicieron copias xilográficas. De esta forma, la gesta del rey Gesar se divulgó de dos modos: a través de canciones orales y mediante copias manuscritas o xilográficas. Las copias xilográficas se han difundido con mayor amplitud, pero la vida del poema ha estado a cargo de los cantantes, que han sido:

the most important factor is reliance upon each singer to hand the tradition down from one generation to the next $[\ldots]$ They are "the people's artists", the artist of the masses; they incarnate the ability and intelligence as well as the spirit of the common person (Zhambei, 280). ${ }^{7}$

\section{Las aspiraciones virtuosas y malignas}

Como preludio al relato de Gesar de Ling, Alexandra David-Néel cuenta que, en una aldea del Tíbet, vivía en el bosque un yogui, un bodisatva, ${ }^{8}$ quien decidió obtener la iluminación, para lo cual, en un acto de suprema compasión por los seres que sufren, ofreció su cuerpo a las bestias hambrientas. ${ }^{9}$

Cerca del lugar habitaban dos mujeres, una madre con su hija, quienes gozaban de una próspera situación. La madre es testigo del mo-

6 "Por otra parte, la épica refleja una sociedad tibetana del siglo vi al IX en vez del siglo x. Así, una conclusión satisfactoria de los orígenes de la épica no puede establecerse sobre la base de la vida histórica de figuras heroicas".

7 "el factor más importante es la confianza en cada bardo que lega hasta el último detalle a la tradición de la generación siguiente y esta a la siguiente. [...] Ellos son los 'artistas del pueblo', los artistas de las masas, encarnan la habilidad y la inteligencia tanto como el espíritu de las personas comunes".

${ }^{8}$ Un bodisatva es un practicante budista del camino del Mahayana, quien ha logrado la iluminación espiritual, pero que posterga su entrada al nirvana para ayudar a otros seres y así también ellos obtengan el despertar de la mente.

${ }^{9}$ En las vidas pasadas del Buda Shakyamuni, se cuenta que él se ofrece como alimento a una tigresa moribunda y hambrienta y a sus debilitados tigritos, para salvarlos de la muerte por hambre. 
mento en el que el bodisatva muere, y observa cómo su energía vital se eleva por el espacio como una luz radiante, que se dirige a la India. Convencida de que el bodisatva se había transformado en esa luz, y que renacería como un Buda en la India, decide dejar todos sus haberes e irse a buscarlo para recibir sus enseñanzas. La hija se niega a dejar sus riquezas $\mathrm{y}$, sin poder comprender la motivación de su madre, furiosa, forja su sino al proferir esta imprecación: "Buda y su Doctrina me importan un bledo" (David-Néel y Yongden, 72).

La anciana parte sola en un largo y difícil viaje a la India. Su hija, mientras tanto, tuvo tres hijos y, con el paso de los años, fue perdiendo todo su patrimonio. En su desesperada confusión, culpa de todas sus desgracias al bodisatva, que había vivido cerca de su casa. Finalmente, sucumbe en la miseria, es abandonada por todos y sus tres hijos mueren poco después. Antes de morir, y con un odio infinito, lanza una nefasta maldición contra el Buda y su doctrina: "Que mis hijos y yo podamos renacer como reyes ricos y poderosos que destruyan definitivamente la doctrina de Buda y a aquellos que la profesan" (75). Este fatal juramento es un anatema y la causa de que ella y sus hijos renazcan como demonios.

Ahora bien, las acciones anteriormente narradas, consideradas desde la perspectiva del budismo, son la causa del nacimiento de los cuatro Reyes Demonios: la primera acción causal es "la ignorancia", ${ }^{10}$ la hija, ofuscada, no reconoce al bodisatva; la segunda acción es cuando en ella emerge una insaciable avidez por sus posesiones materiales, esto es "el apego a lo material o la codicia"; finalmente, en el momento en que todos sus bienes se disipan, y aún más, sus hijos mueren y pierde la vida, emerge una incontrolable "ira" que la ciega completamente y le produ-

\footnotetext{
${ }^{10}$ Explica Matthieu Ricard que: "In Buddhist terms, ignorance is not just a lack of knowledge or information. It is, rather, a persistent blindness to the true nature of mind and phenomena. It is ignorance that divides things into self and other, near and far, good and bad, and that see things as having a true, substantial existence" (Ricard apud Linrothe y Watt, xv). "En términos budistas, la ignorancia no es solo la falta de conocimiento o información. Es, más bien, una persistente ceguera a la verdadera naturaleza de la mente y los fenómenos. Es la ignorancia que divide las cosas en sí mismas y otras, cercanas y lejanas, buenas y malas, y que ven las cosas como teniendo una verdadera y sustancial existencia".
} 
ce una delirante sed de venganza. Consecuentemente, sus acciones son las que determinan la forma en que ella y sus hijos renacerán.

Estas tres emociones obstructivas, según el budismo, son los llamados "tres venenos", que originan otras innumerables aflicciones nocivas y son representadas, en la Rueda de la Vida, como el eje central e impulsor de los continuos renacimientos de los seres en los seis reinos del samsara (figura 1). ${ }^{11}$

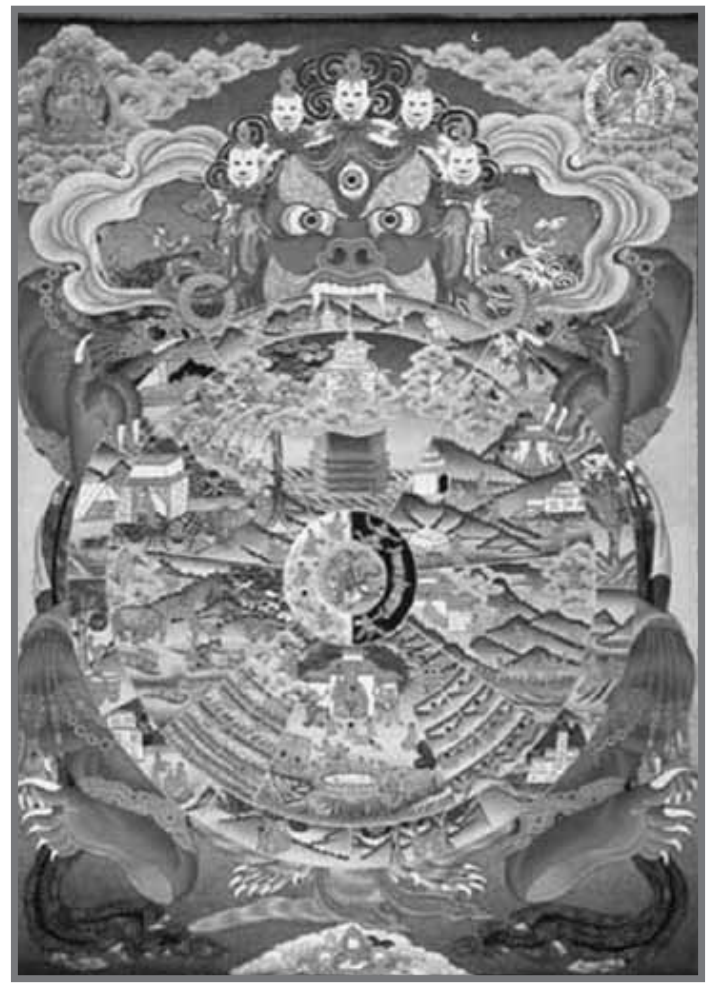

Figura 1. La Rueda de la Vida

${ }^{11}$ La Rueda de la Vida está constituida por seis reinos de existencia, que se dividen en dos niveles. Los tres primeros reinos corresponden a un nivel superior y son el reino de los devas o dioses, el de los asuras o semidioses o titanes, y el de los hombres. El nivel inferior está formado por los reinos de los pretas o 'espíritus hambrientos', el de los animales, y el de los narakas o 'demonios'. Iconográficamente se les representa en la Rueda de la Vida. Para una descripción detallada de la cosmología budista, ver Jamön Kongtrul Londrö Tayé, Myriad of Worlds. 
Así, aquellos que tienen la "aspiración" de trabajar para beneficio de los demás, renacerán como bodisatvas, y los que actúan con "aspiraciones" dañinas, hacen voto de oponerse al budismo y de causar daño a los demás, renacerán como "demonios". La "aspiración" no es solo un propósito, sino una plegaria para obtener lo deseado, y tiene la fuerza de un voto.

En el relato épico, el enfrentamiento entre las aspiraciones positivas y negativas inicia el rompimiento de una situación narrativa armoniosa, y todos los episodios posteriores se estructuran para terminar con el conflicto y volver a armonizar la situación inicial del relato. "The existence of such creatures, demons and bodihisattvas, with their conflicting intentions, is the first or realist cause of the action of the epic" (Kornman, 35). ${ }^{12}$

\section{Naturaleza de los "demonios" en Occidente}

En la cultura occidental, la figura mítico religiosa del "demonio" tiene connotaciones y funciones diferentes y aún contrarias a las del budismo. En el Occidente, el término demonio ha sido aplicado principalmente por la religión judeocristiana como lo opuesto a lo divino.

El vocablo demonio proviene del griego daimon, que se vincula con el espíritu divino, sabio y poderoso. En los diálogos platónicos se tiene información sobre esta entidad. Se distinguen tres tipos de demonios: el primero está constituido por cada uno de los guardianes de los individuos, que los guían en el transcurso de la vida y los conducen, después de su muerte, ante los jueces. El segundo son los demonios-almas, dadas a cada hombre en su nacimiento; es el elemento demoníaco de su naturaleza y proviene del Demiurgo. "El tercer tipo sirve de intermediario entre los hombres y los dioses, los ejemplos son el Amor y el Sueño" (González Ochoa, 83). En el Banquete, Sócrates pregunta a Diótima por la naturaleza del Amor:

12 "La existencia de estas criaturas, demonios y bodisatvas, con sus conflictivas intenciones, es la primera causa de la acción de la épica". 
—Pero, en fin Diótima, ¿qué es [el amor]? —Un gran demonio, Sócrates, puesto que todo lo demoníaco está entre lo divino y lo mortal (Platón, 300).

"Este tercer tipo de demonio es una consecuencia lógica del pensamiento platónico. Una de sus leyes generales es que no pueden existir relaciones directas entre una cosa y otra, si se trata de relaciones entre seres que pertenecen a jerarquías distintas, como es el caso de dioses y hombres" (González Ochoa, 84). De esta manera, el demonio, para la filosofía platónica, es una categoría necesaria, con la cual se establece el principio de la tríada, figura que permite unir los polos opuestos y armonizan los contrarios.

La idea de los demonios como el mal es obra del cristianismo, que a su vez se apoya en el pensamiento judío que considera al demonio como un ángel caído. Ezequiel en el Antiguo Testamento refiere el motivo de la caída del príncipe de Sor-r:

Por cuanto se ha ensoberbecido tu corazón y has dicho: Dios soy yo [...] a causa de tu hermosura has corrompido tu sabiduría con motivo de tu esplendor; por eso, te echo a la tierra [...] has venido a ser símbolo del terror (cap. XXVIII, 2, 17, 19).

En el Nuevo Testamento, en el Apocalipsis, el término demonio adquiere otras significaciones; no solo es el ángel caído, sino que se trasforma en el enemigo acérrimo y pérfido de Dios, que se enfrenta a los poderes celestiales. Además, el término demonio adquiere otros valores conceptuales: se le llama Diablo "calumniador" y Satanás "adversario", y se le representa en la tremebunda figura de un dragón.

En el aspecto teológico, la tradición cristiana se aparta de la noción platónica que considera al demonio como un mediador entre los dioses y los hombres. San Agustín, en desacuerdo con la propuesta platónica, exclama: “¡Buena cosa es la santidad de Dios! No tiene comunicación con el hombre que le ruega, pero la tiene con un demonio que actúa insolentemente. No tiene comunicación con un hombre lleno de arrepentimiento, pero la tiene con un demonio lleno de trampas" (González Ochoa, 96). Por ello, considera que el demonio no puede ser mediador 
entre los dioses y los hombres, sino que es la personificación de una entidad malévola, que urde trampas para el hombre y es enemiga de Dios, y que, si bien es un ser eterno, y en este sentido cercano a lo celestial, es de naturaleza perversa, por lo tanto inferior y contrario a lo divino.

San Agustín fija algunos de los rasgos que van a definir y precisar la personificación del demonio en el pensamiento cristiano. Así, dice que los demonios

son espíritus fanáticamente inclinados a hacer daño, completamente ajenos a la justicia, llenos de orgullo, verdes de envidia y con buena práctica en engañar, que viven en el aire, pero lo hacen porque han sido expulsados de las regiones sublimes de las alturas del cielo y fueron condenados en el principio a habitar esta región, que es como si fuera su prisión apropiada a su naturaleza, en justo castigo por una trasgresión de la cual no hay refugio (san Agustín apud González Ochoa, 96).

De esta manera, en la cultura occidental, la figura del Demonio, Diablo o Satanás, fue creada, principalmente, por la visión teológica cristiana. Por otra parte, el catolicismo es una religión sustentada en dogmas, por lo que la personalidad del Demonio, si bien puede tener alguna variación en sus rasgos, siempre representa lo opuesto a lo celeste y al bien. Para el cristianismo, la culminación de sus enseñanzas es liberarse del pecado original y de los cometidos en vida, y, después de la muerte, morar en la gloria de Dios: esto es liberarse del dominio demoníaco simbolizado en el pecado.

En la fe católica, la condición de cada uno de los seres es distinta: los animales, los hombres, los ángeles y los demonios tienen una categoría y estado diferentes e inmutables; en el caso de los demonios, su naturaleza es malévola, opuesta a la celestial; son enemigos del hombre e inferiores en la escala cosmológica, y además, no tienen posibilidad de transformación o modificación.

\section{Los demonios tibetanos: Narakas, Dharmapalas $e$ Yidams}

En el budismo tibetano, las representaciones iconográficas de las deidades iracundas en las thankas (pinturas con deidades budistas) y en los 
murales de los monasterios, pueden horrorizar a un observador neófito, ajeno a esta cultura, porque posiblemente interpreten que: "the images seem to come directly from Dante's Inferno; scenes of death and destruction, decapitation, monstrous beings with garlands of severed heads gorging on human hearts, in short, a human hell more terrifying than any horror movie" (Rubin, vi). ${ }^{13}$

Esta fue la impresión que tuvieron algunos de los primeros viajeros occidentales que visitaron el Tíbet, dado que, en su forma de percepción, subyacían las imágenes aterradoras de los diablos y demonios occidentales. Austine Waddell, quien, entre finales del siglo XIX y principios del xx, publicó varios libros sobre esta región, describe la conmoción que tuvo al ingresar a una sala dedicada a los protectores iracundos en el Tíbet:

One of the rooms was the Devils' Chamber of horror (Gon-k'ang), a sort of satanic Aladdin's cave in the dark, designed to awe and impress the superstitious pilgrims. Here are collected the hideous colossal images of all the demons which infest the word and prey upon the poor Tibetans. They have the forms of men, but the heads of ogres ad monstrous beast, the hideous creations of a nightmare, and all are eating human bodies and surrounded by variety of weapons (Waddell apud Linrothe, 25). ${ }^{14}$

Sin embargo, a pesar de este aparente cuadro de horror, cada una de estas figuras, los ornamentos que ostentan, los símbolos que las rodean, el séquito que las acompaña y el entorno flameante y tenebroso, tienen un significado muy diferente al que una mirada inculta e inexperta imagina. En el budismo, las figuras demoníacas tienen funciones y signifi-

13 "las imágenes parecieran venir directamente del Infierno de Dante: escenas de muerte y destrucción, decapitación, monstruosos seres con guirnaldas de cabezas cortadas, devorando corazones humanos, en resumen un infierno humano más terrífico que cualquier cine de terror".

14 "Uno de los cuartos era la Capilla del Horror de los Diablos, una suerte de cueva satánica de Aladino en la oscuridad, diseñada para atemorizar e impresionar a los supersticiosos peregrinos. Aquí se recogen las horrendas y colosales imágenes de todos los demonios que infestan el mundo y se aprovechan de los pobres tibetanos. Tienen las formas de hombres, pero las cabezas de ogros y bestias monstruosas, la aterradora creación de una pesadilla, y todos están comiendo los cuerpos humanos y rodeados por una variedad de armas". 
cados distintos y aun contrarios a las que el Occidente ha dado a esta clase de imágenes. Si bien no es este el lugar para hacer un resumen del pensamiento budista, considero que es necesario señalar uno de los puntos divergentes entre el budismo y el cristianismo: el objetivo final de las enseñanzas budistas, en el Hinayana, en el Mahayana y en el Vajrayana, es obtener el despertar o la iluminación de la mente, esto es, morar en el nirvana o, en otros términos, reconocer la naturaleza primordial de la mente. "The wrath of the Vidyarajas (wrathful 'kings of wisdom'), their weapons and the blazing flames of their aureoles are directed against the darkness of avidya (ignorance), which prevents men form gaining emancipation. They are therefore really beneficent" (Dietrich Seckel apud Linrothe, 4). ${ }^{15}$

El budismo, contrariamente al cristianismo, considera que la condición ontológica innata de todos los seres vivientes es su naturaleza búdica; esto es, todos los seres vivientes poseen la innata potencialidad para obtener la iluminación. En sánscrito, esto se llama tathagatagarbha, que literalmente se traduce como la esencia o matriz de los Thathagatas (de tatha "aquellos" + gata, que se han "ido" o "arribado"), esto es, de los Budas. De esta suerte, no hay ningún ser viviente cuya naturaleza sea esencialmente demoníaca o esté manchada por un pecado original, o que haya diferencia entre las diversas clases de seres, porque todos los seres vivientes tienen la misma naturaleza búdica.

\section{La naturaleza de los "demonios" en el budismo tibetano}

El término demonio abarca distintas categorías de seres en esta cultura; la que se parece más al demonio occidental es la de los seres que moran en el reino del infierno, los llamados Narakas. El reino del infierno, en la Rueda de la Vida, es la representación del espacio en el cual renacen los seres que han acumulado karma negativo en sus diversas vidas (figura 2). La permanencia en el reino de los infiernos es muy larga, pero

15 "La ira de los Vidyarajas (los furiosos reyes de la sabiduría), sus armas y las ardientes llamas de su aureola están dirigidas contra las tinieblas de avidya (la ignorancia), que impide que los hombres obtengan su liberación, y por consiguiente es muy benéfica". 


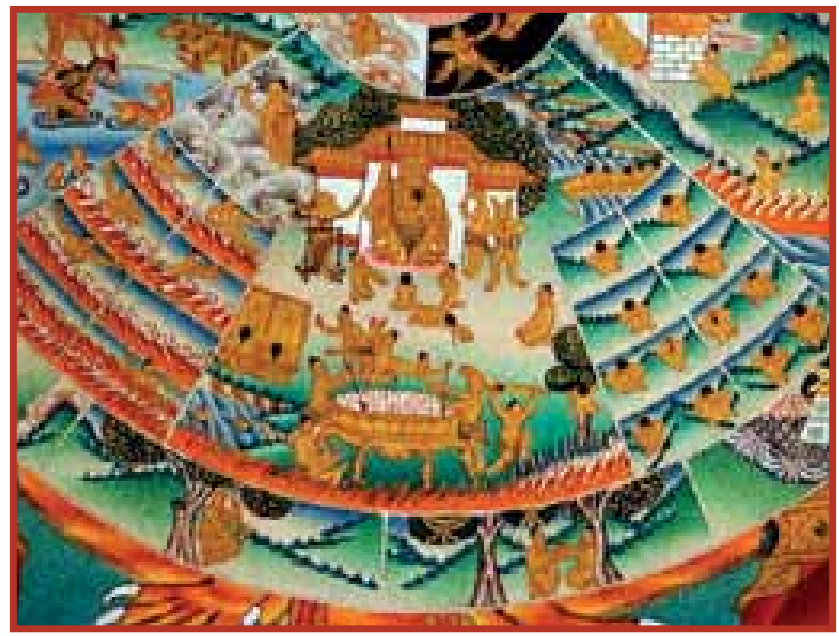

Figura 2. El reino de los infiernos en La Rueda de la Vida

no eterna. Una vez que el karma negativo de estos seres se agota, o acumulan algún acto positivo, pueden trasmigrar a otro reino.

Otras figuras con apariencia demoníaca son las imágenes de las deidades búdicas representadas con actitudes coléricas; estas deidades asumen esta apariencia iracunda, de acuerdo a las funciones que desempeñan en la cosmología budista, y al deber y responsabilidad que se les han otorgado. Estas representaciones, en general, se llaman los Dharmapalas, que son los "protectores del dharma" (las enseñanzas budistas). La tarea que tienen asignada es, principalmente, la de proteger la institución budista contra los adversarios, así como preservar la integridad de las enseñanzas. De aquí que su aspecto sea el de seres fieros, en acción iracunda y agresiva, con múltiples armas y ornamentos terroríficos, rodeados de fuego y acompañados de una comitiva también de seres coléricos y fieros animales.

Estas iracundas deidades protectoras son seres que poseen cuerpos de baja estatura, pero fornidos, con fuertes extremidades; muchos de ellos tienen varias cabezas y un gran número de manos y pies. Los rostros de estas deidades poseen una típica expresión airada: la boca está retorcida con una sonrisa enfurecida; de sus comisuras sobresalen largos colmillos, que a menudo se dice que son de cobre o hierro; a veces, los dien- 
tes superiores muerden el labio inferior. Una "niebla de enfermedades" proviene de la boca, y una tremenda tormenta está soplando desde sus fosas nasales. Bajo la protuberante frente, están los ojos inyectados de sangre, que lanzan una mirada encolerizada, y generalmente un tercer ojo está visible en el medio de la frente.

Este grupo de protectores y deidades se divide en tres ramas: la primera es la de los protectores poderosos, las deidades femeninas y masculinas de alto rango, que han pasado más allá de las seis esferas de existencia; se les ha llamado "protectores ultramundanos o protectores iluminados" (Nebesky-Wojkowitz, 4).

Los protectores iluminados, en general, son los que resguardan una práctica budista, un linaje o un ritual en particular, y milagrosamente descubren termas (textos o tesoros escondidos). "These teaching tend to require initiations in order to be reveled and psychically dangerous to practice. Therefore, initiations call for special protectors to ensure the safety and mental stability of the initiate at a time of vulnerability" (Linrothe y Watt, 18). ${ }^{16}$

Entre los protectores iluminados se encuentran Yama Dharmaraja (figura 3), vinculado con Tsongkapa (13571419) y con el linaje Gelupa; Palden Lhamo (figura 4), quien es la protectora de la capital del Tíbet y, además,

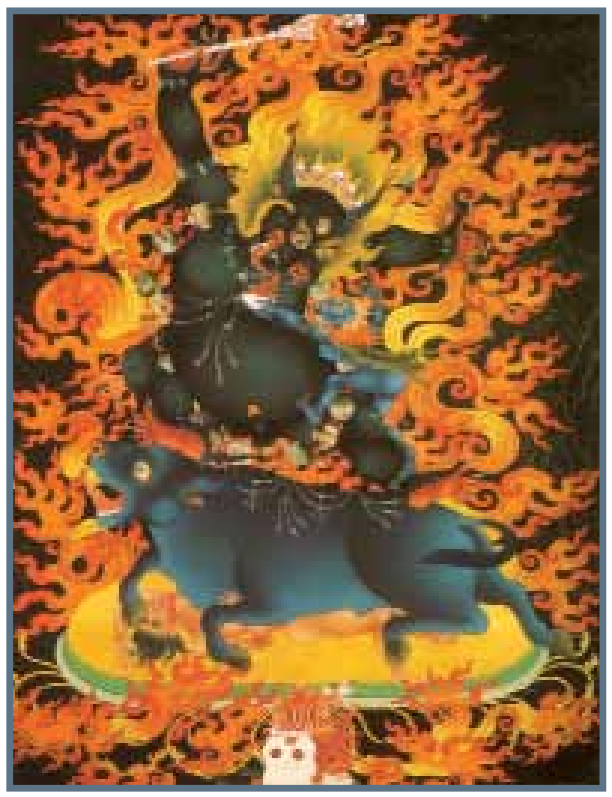

FIGURA 3. Yama Dharmaraja

16 "Estas enseñanzas tienden a requerir iniciaciones con el fin de ser celebradas y psicológicamente peligrosas en la práctica. Por lo tanto, las iniciaciones convocan a protectores especiales para garantizar la seguridad y estabilidad mental de un iniciado en un momento de vulnerabilidad". 




FIGURA 4. Palden Lhamo 
de los Dalai Lamas (Nebesky-Wojkowitz, 23-24); Mahakala (figura 5), deidad que es representada en múltiples formas, con dos, cuatro o múltiples manos; cada una de esas formas protege a los seres, en distintas situaciones, y a los diferentes linajes budistas. Estas deidades residen en una esfera exterior; por ello se les llama extra o ultra mundanos, pero tienen una parte activa muy fuerte en la vida religiosa tibetana, y algunos de ellos llegan a tomar posesión de los médiums, los que actúan como portavoces de la deidad, durante ceremonias especiales.

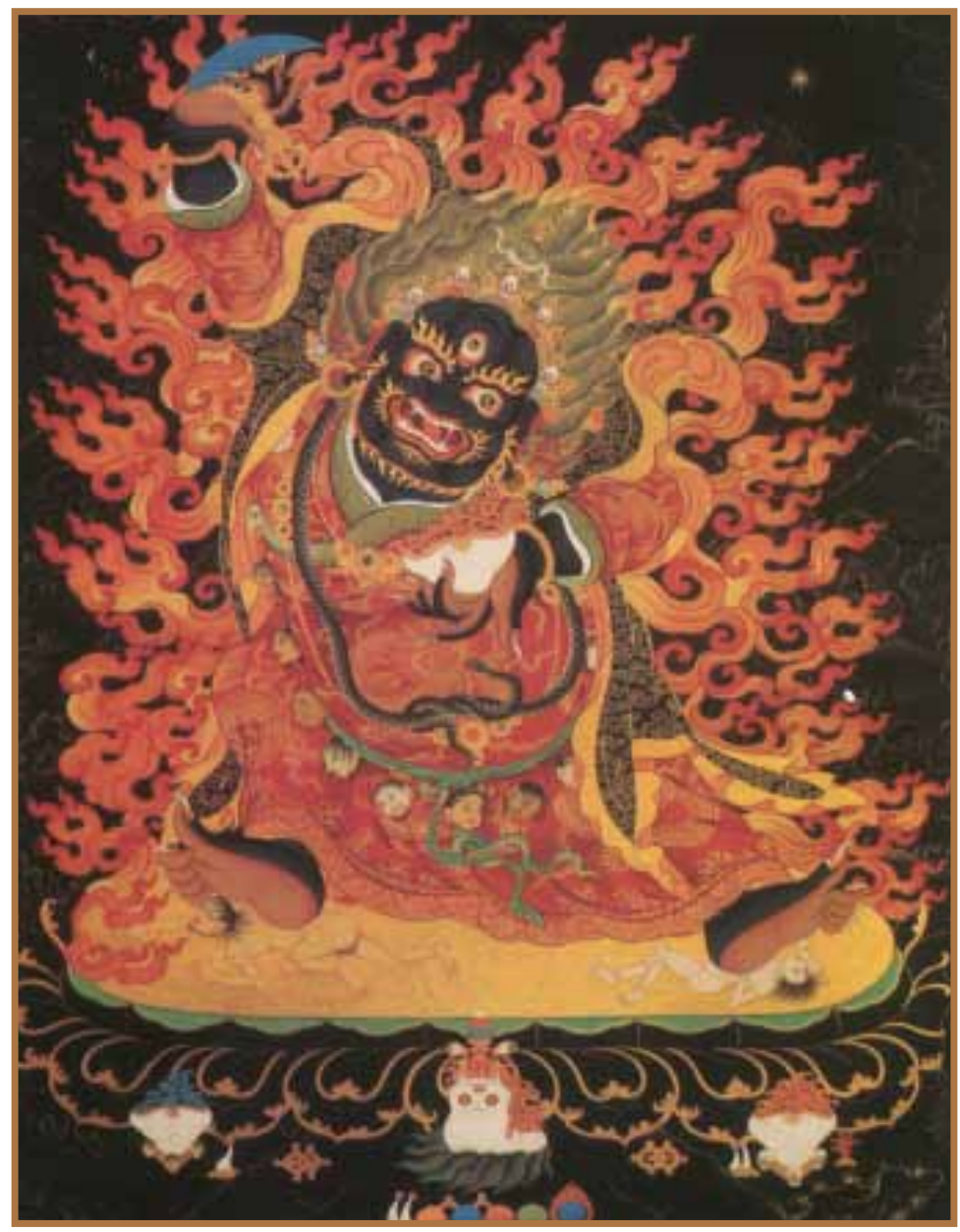

FIGURA 5. Mahakala 
La segunda rama son los "protectores mundanos o peligrosos". Algunos de ellos tienen su origen en deidades prebudistas o en espíritus selváticos o de las montañas, que en otro tiempo fueron enemigos del budismo, cuando este llegó al Tíbet entre los siglos VII y VIII. Un gran número de ellos fueron subyugados por Padmasambhava, cuando este gran yogui arribó al Tíbet, en el siglo vIII, y, posteriormente, por los grandes practicantes y yoguis budistas; de esta forma, fueron convertidos en guardianes del budismo y están "atados por un juramento". Su función es la de proteger al budismo, "but the primary responsibilities are more mundane: to ensure the birth of sons, to protect humans and livestock against diseases and epidemics, to avert accidents and bad omens, and to destroy or contain obstacle-creating demons" (Linrothe y Watt, 17-18). ${ }^{17}$ Muchos de ellos montan animales salvajes como leones, cabras y toros, y visten armadura y botas, que los identifican como guerreros. Entre estos protectores mundanos se encuentran Rahula (figura 6), Dorje Legpa, Vaishravana, Pehar y otros.

Una tercera categoría es la de los Budas Airados, también llamados Yidams. Son deidades búdicas que, aunque se manifiestan en forma furiosa, son Budas o Bodisatvas totalmente iluminados que desempeñan actividades diferentes. Cada una de estas deidades manifiesta distintas capacidades; así, el aspecto colérico de Vajrasattva (figura 7), el buda de la Purificación, se transforma en Vajrakilaya (figura 8), que personifica la Actividad Iluminada de todos los Budas; Manjushri (figura 9), el buda de la Suprema Sabiduría, toma la figura de Yamantaka (figura 3), el Exterminador de la Muerte, etcétera.

Los Budas Airados, bajo su apariencia de seres iracundos, beligerantes y poderosos, expresan una actividad enérgica briosa, inagotable y omnipotente, dirigida a proteger y ayudar a los seres vivientes; asimismo, cumplen con la actividad de Yidams, que,

They are what known as "tutelary deities", sometimes called "archetype deities", withe a personal connection to aspirants. [...] In Esoteric Buddhist practice, one visualizes one of these deities as emanating in front of

17 “pero su primaria responsabilidad es más mundana: proteger a los humanos y a los animales contra las enfermedades y las epidemias, evitar accidentes y malos presagios y destruir o contener obstáculos creados por demonios". 


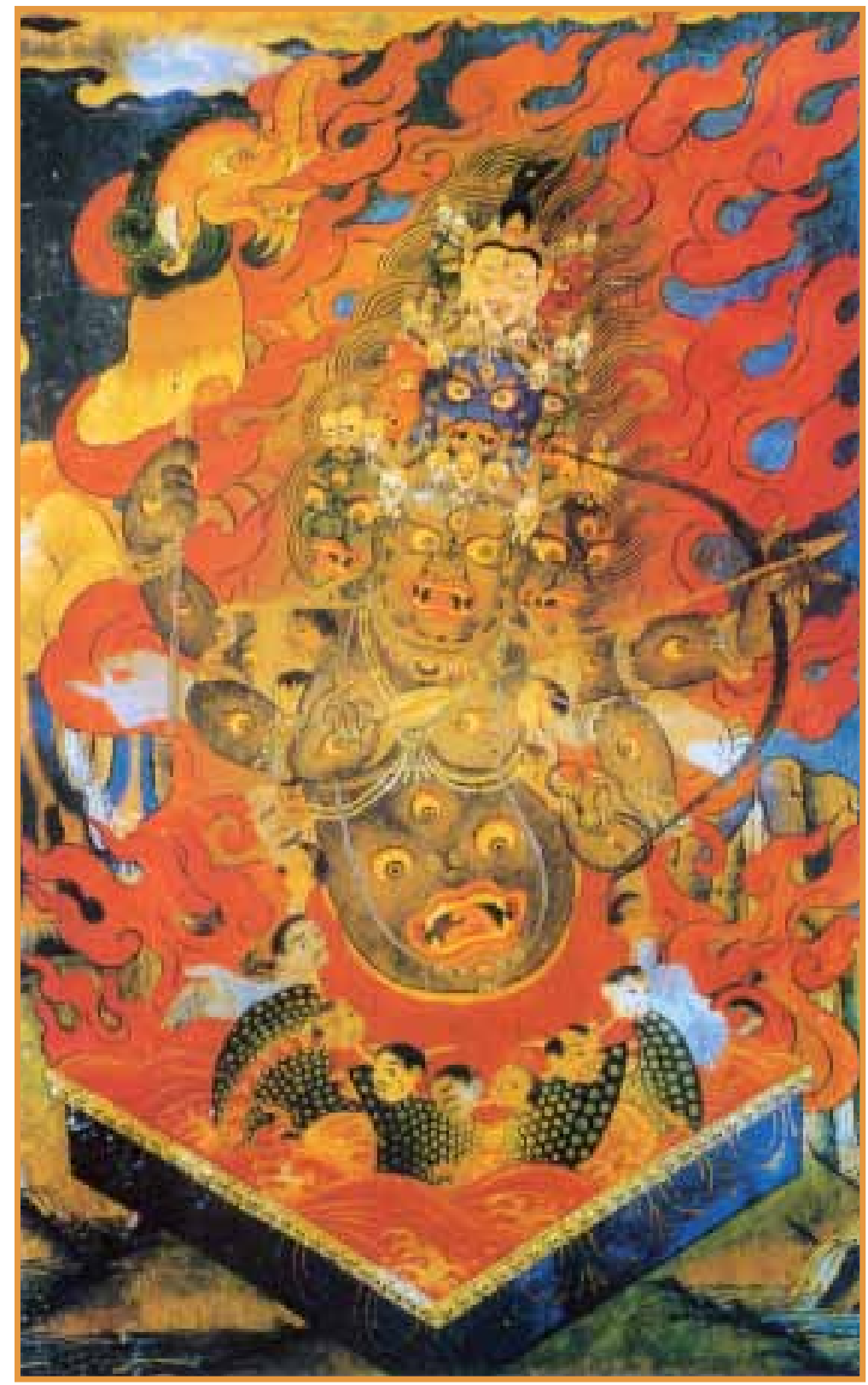

Figura 6. Rahula 


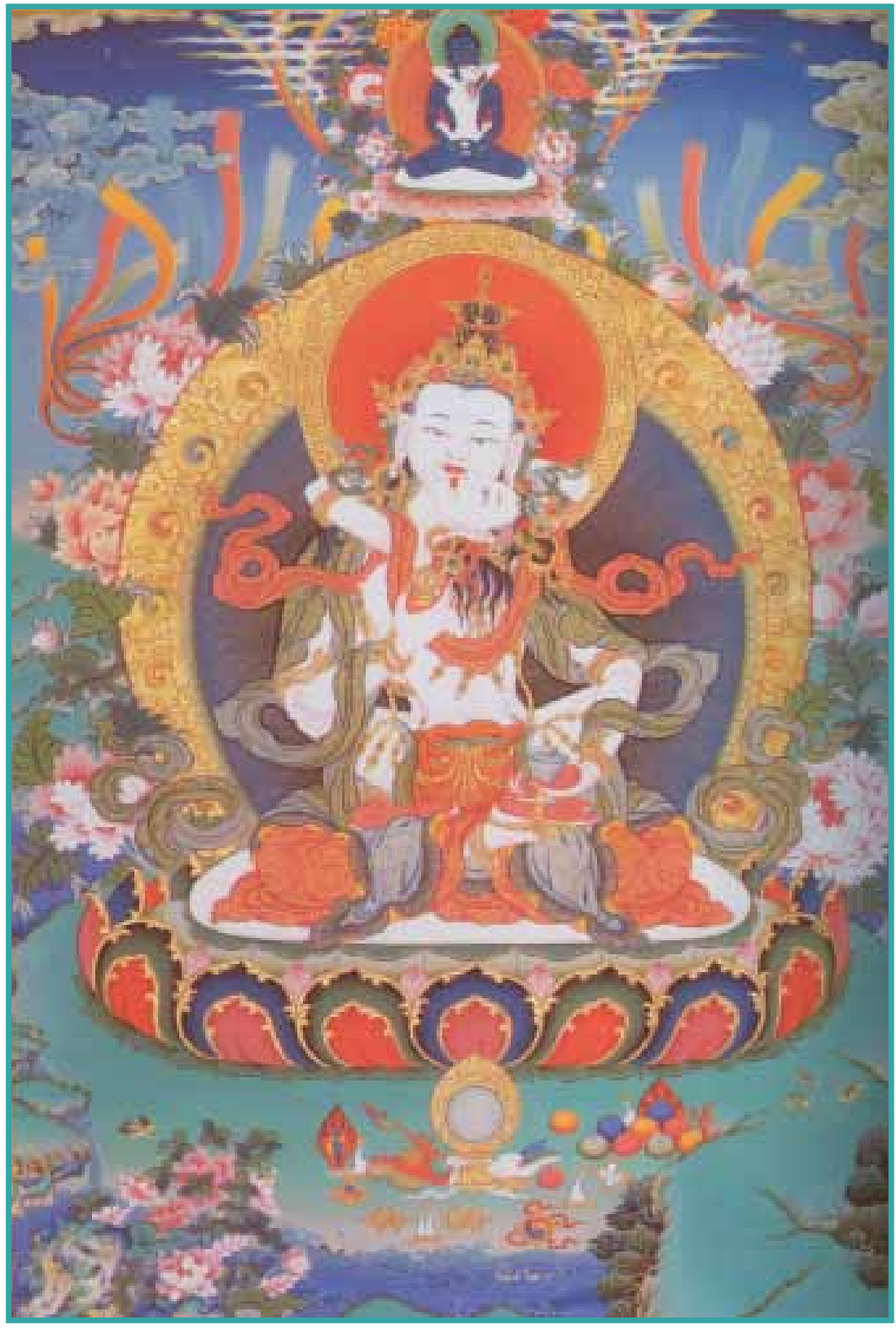

Figura 7. Vajrasattva 


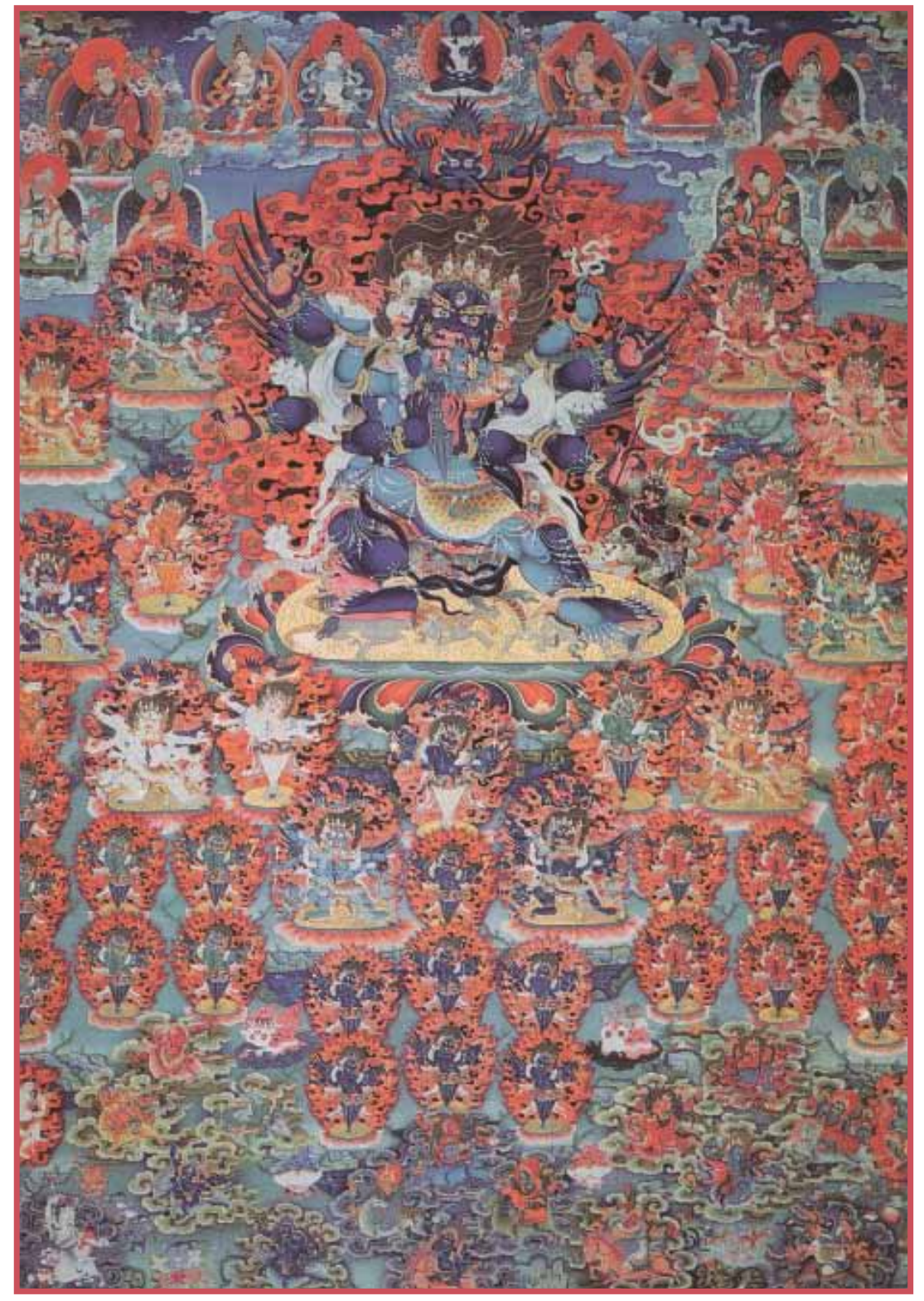

FIgURA 8. Vajrakilaya 


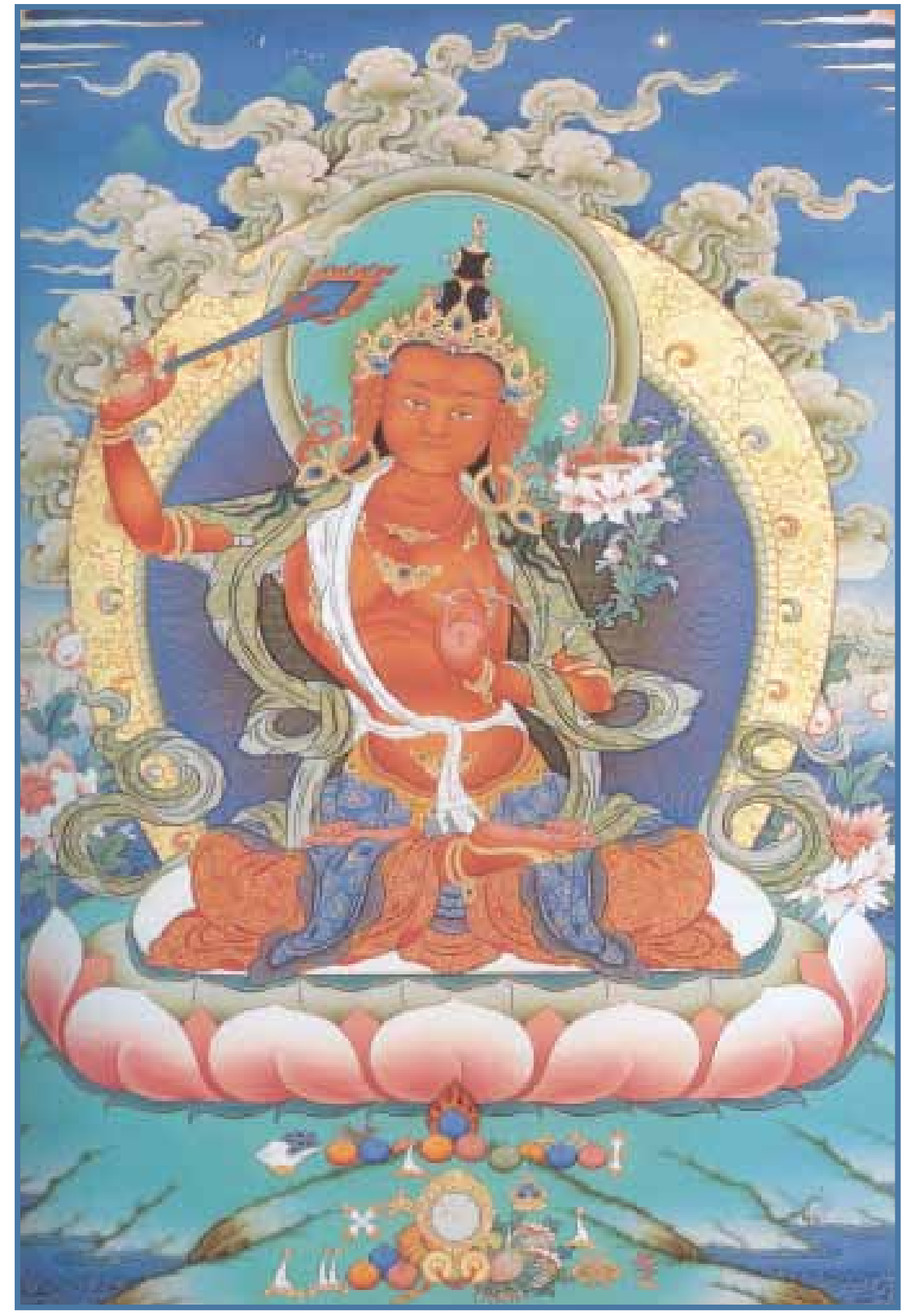

Figura 9. Manjushri 
you. You offer him/her praise and veneration, but then visualize yourself as becoming identical to the deity, followed in due course by dissolution of the union $[\ldots]$ and cultivate a sense of divine pried the strong feeling...that you are the actual fully enlightened emanation body of a Buddha (Linrothe y Watt, 20). ${ }^{18}$

Entre algunos de los Yidams se encuentran: Hayagriva, Vajrakilaya, Guhyasamaja, Yamantaka, Hevajra, Chakrasamvara (figura 10), Vajrayogini, Kalachakra, etcétera.

Así pues, estas tres clases de seres coléricos (los protectores mundanos, los protectores iluminados y los Yidams) tienen funciones protectoras semejantes, aunque no siempre idénticas. De esta manera, los protectores iluminados protegen el dharma y distribuyen bendiciones y favores contra la enfermedad y otros peligros personales; los protectores mundanos, que están bajo juramento, protegen el dharma y son invocados para proteger a los practicantes en su vida física, cotidiana y material; los Budas Airados o Yidams proveen de ambas dádivas, pero en especial son un medio para que los practicantes logren la transformación mental y la total iluminación (23).

Pese a su apariencia terrorífica, los Dharmapalas son deidades que defienden y ayudan a los seres vivientes; su apariencia violenta corresponde a lo que se puede llamar la "actividad colérica divina" en inagotable dinamismo, que combate permanentemente las obstrucciones mentales de los seres vivientes para que estos puedan reconocer su naturaleza búdica y obtengan el estado mental del nirvana.

\section{Los demonios en la épica de Gesar de Ling}

En la épica de Gesar de Ling, la mujer y sus hijos, que renacen como demonios para combatir el dharma, son personificados por Lutzen, al

18 "Ellos son los que conocemos como 'deidades tutelares' con una conexión personal con los aspirantes [...]. En el budismo esotérico se practica [durante la meditación] la visualización de una de estas deidades como emanando en frente del practicante. Después, tú ofreces a él o ella alabanza y veneración, pero en seguida tú mismo te transformas idéntico a la deidad, en seguida, a su debido momento, se disuelve la unión [...] y se cultiva la sensación del orgullo divino y el fuerte sentimiento de que se es la emanación del cuerpo de un buda totalmente iluminado". 


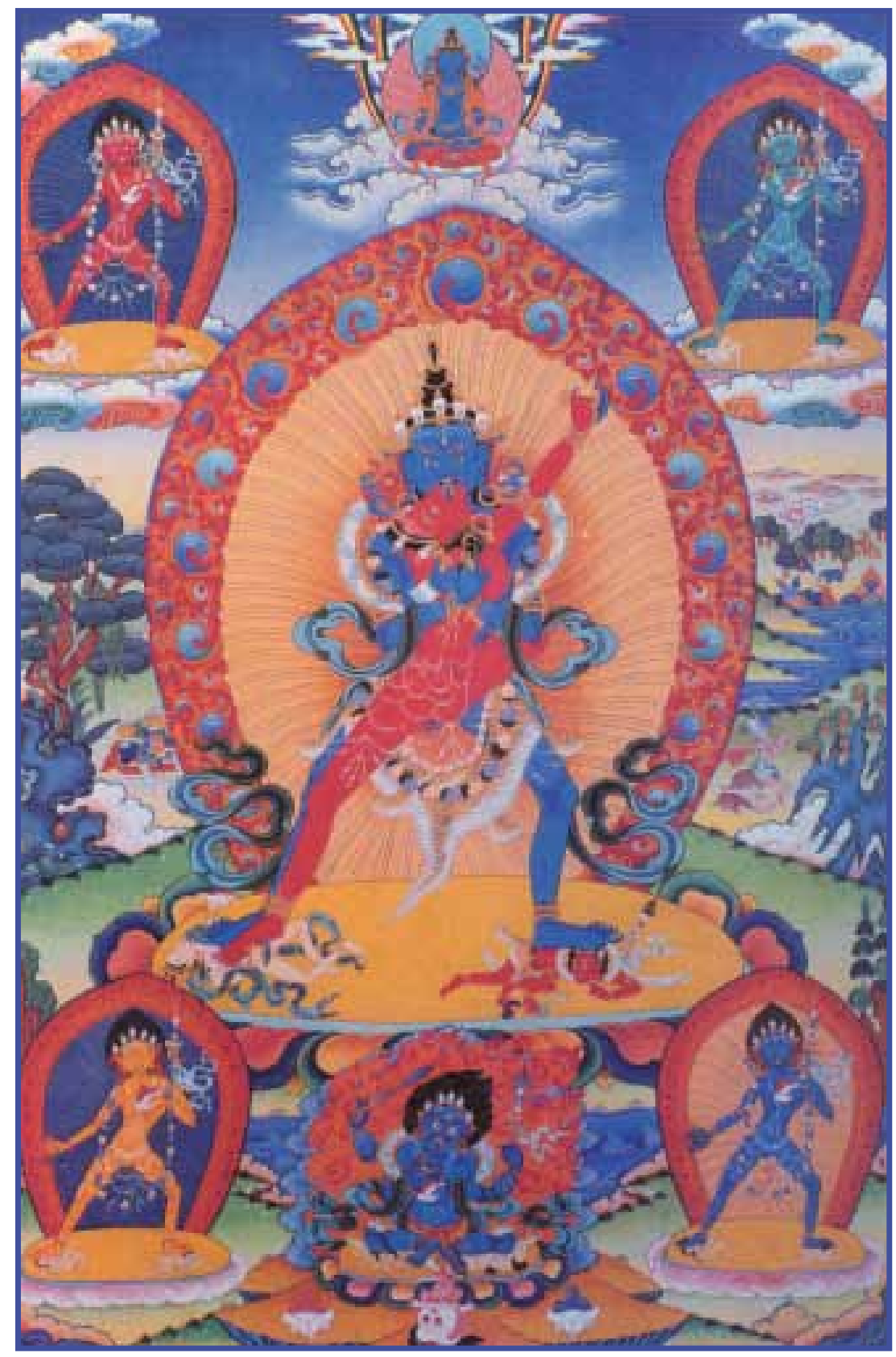

FIGURA 10. Chakrasamvara 
Norte; Kurkar, al Este; Satham al Oeste, y Shingti, al Sur. Gesar de Ling se enfrenta con éxito a estos demonios, gracias a sus atributos divinos y con la ayuda de las deidades celestiales; esto se debe a que él es la reencarnación de una deidad, enviada para combatir y exterminar a los opositores del dharma.

Los cuatro demonios tienen un aspecto aterrador: Lutzen es descrito como un gigante; "su cabeza alcanza el cielo, aun cuando sus pies siguen tocando la tierra. Su lengua es una llama serpentina como el rayo" (David-Néel y Yongden, 156), y se come a los seres vivos. Gesar se enfrenta a este demonio y le clava una flecha en el único punto vulnerable que tenía el demonio. Pero, una vez que lo ha matado, induce a la energía vital a renacer en el Paraíso del Oeste (figura 11). De igual forma,

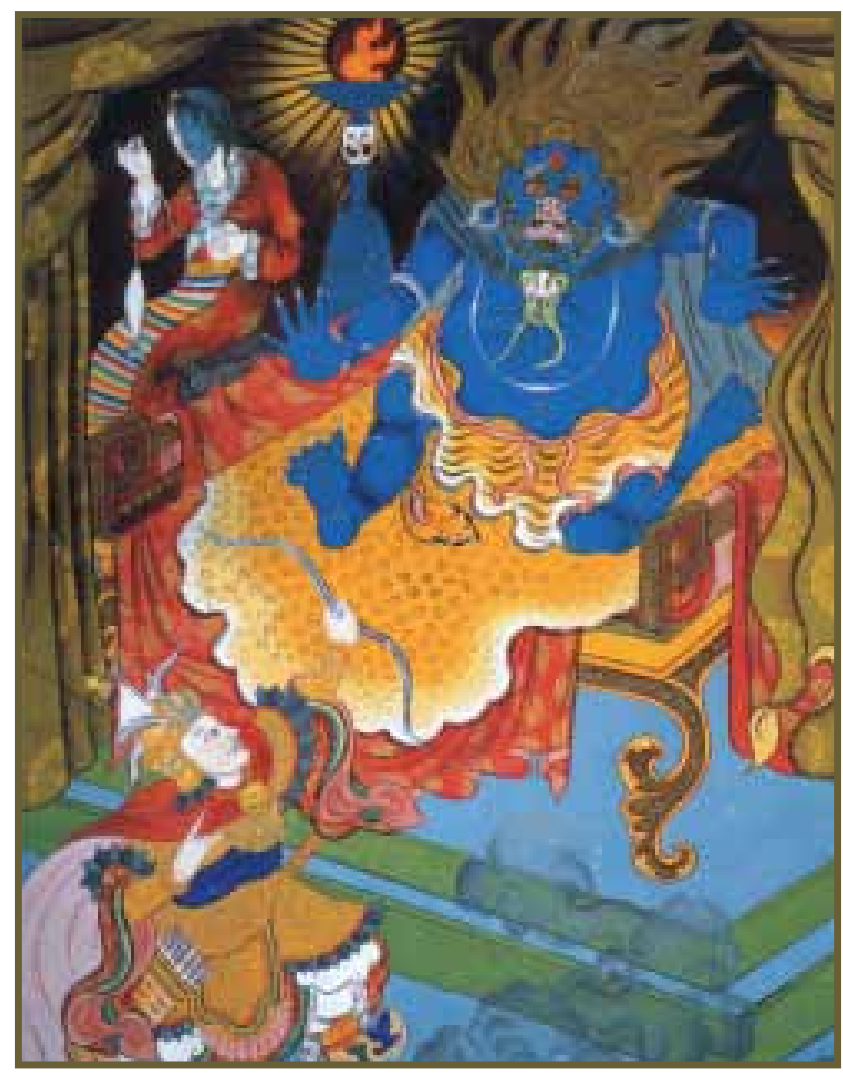

Figura 11. Gesar de Ling y Lutzen 
Gesar cortó la cabeza de Kurkar, y "concentrando sus pensamientos, dirigió el espíritu de Kurkar al Paraíso del Oeste". Para derrotar a Satham, demonio muy poderoso, Gesar se convierte en una abeja con afiladas alas que entra por la boca del demonio y lo destruye interiormente; luego, convierte su espíritu en una mosca que vuela también hacia el Paraíso. Por último, Shingti cayó en medio de la ciudad en llamas (267-268).

Gesar de Ling no solo libera a los Reyes Demonios de su estado inferior, sino que se impone la tarea de transmutar a los súbditos de estos reyes, que habían muerto durante las guerras y que también eran demonios:

En el transcurso de las guerras que acabo de terminar, he matado a muchos seres y muchos más tienen que ser todavía muertos por los guerreros bajo mi mando. Debo guiar a los "espíritus" de los desafortunados difuntos a los lugares de morada feliz. Por ello, voy a retirarme a un lugar apartado de palacio y viviré allí como recluso durante trece años para poder llevar a cabo este deber (270).

Los cuatro Reyes Demonios y sus súbditos fueron subyugados y transmigrados a un nivel superior de vida. De esta manera, se puede considerar que dichos personajes entran en la categoría de protectores mundanos. La práctica de transformar a las fuerzas primigenias, telúricas o demoníacas, en Dharmapalas fue fundamental en el inicio del budismo tibetano (siglos VII-VIII):

No ritual could be performed until the space had been seized from the local spirit, no temple could be built until the site had been forcefully secured, and no Tibet could be converted without the subjugation of is local gods, demons and peoples (Dalton, 111). ${ }^{19}$

Es difícil entender, desde una perspectiva occidental, la visión, que la cultura tibetana tenía (y aún parte de la población tiene) de la realidad, y esta es la mayor diferencia con la categoría que el Occidente le otorga

19 "No podía ejecutarse ningún ritual hasta que el espacio hubiera sido incautado a los espíritus locales, ningún templo podía construirse hasta que el sitio hubiera sido firmemente amparado y el Tíbet no podía ser convertido sin la subyugación de sus dioses locales y demonios". 
a los demonios. En el entorno tibetano convivían (y conviven) tanto los nómadas, aldeanos, monjes, guerreros, etc., así como los budas, los poderosos seres que habitaban las montañas, las aguas, los bosques y todos ellos integraban (e integran) la realidad cotidiana.

In the Tibetan worldview, the boundary between the human and nonhuman world is permeable. Enlightened beings sometimes incarnating the world, taking on human form. At other times they appear to human beings in visions and dreams. Highly accomplished adepts sometimes travel to celestial realms [...]. Lesser spirits, of course, are also active agents in the world, acting at times to help, and at other times to hider human beings in their pursuit of both worldly and spiritual goals (Cabezón, 4). ${ }^{20}$

Por otro lado, hay que considerar que el panteón tibetano es uno de los más extensos entre las distintas religiones del mundo, y tiene diferentes orígenes, de aquí su complejidad y riqueza. Por ello, la categoría de los demonios tibetanos es heterogénea y extensa, y no es una noción abstracta, ética o filosófica, sino una realidad viva.

\section{REFERENCIAS}

CABezón, José Ignacio, Tibetan Ritual, Oxford, Oxford University Press, 2010. Dalton, Jacob P., The Taming of the Demons. Violence and Liberation in Tibetan Buddhism, New Haven, Yale University Press, 2011.

DAvid-NéEL, Alexandra y Lama Yongden, La vida sobrehumana de Gesar. La gran epopeya del Tíbet, trad. Alfonso Colodrón Gómez, Vitoria, España, La llave, 2000.

Francke, August Hermann, A Lower Ladakhi Version of the Kesar Saga, New Delhi, Asian Education Services, 2000.

GonzÁlez OchoA, César, "En torno a una historia de los demonios", Acta Poetica, 12, 1991, 83-98.

20 "En la cosmovisión tibetana, la frontera entre el mundo humano y no humano es permeable. A veces, los seres iluminados se encarnan en el mundo y toman forma humana. Otras veces, se aparecen a los seres humanos como visiones o sueños. Los adeptos, algunas veces, viajan a los reinos celestes [...]. Los espíritus menores, desde luego, también son agentes activos en el mundo, actúan para ayudar o para obstaculizar a los seres humanos". 
Gyamco, Jambian y Zhou Aiming, An Ilustrated Manual of the Tibetan Epic Gesar, Beijing, China Pictorial Publishing House, 2003.

Kongtrul, Londrö Tayé, Myriad of Worlds. Buddhist Cosmology in Abhidharma, Kâlacakra, and Dzogchen, New York, Snow Lion Publications, 1995.

Kornman, Robin Brooks, Ph.D., A Comparative Study of Buddhist Version of the "Epic of Gesar of Ling", vol. I y II, A Dissertation Presented to the Faculty of Princeton Univesity in Candidacy for the Degree of Doctor of Philosophy, Princeton University, 1995.

La BiBLiA, versión de León Dujovne, Manasés Konstantynowski y Moisés Konstantynowski, Buenos Aires, Sigal, 1998.

Lianrong Li, "History and the Tibetan Epic Gesar", Oral Tradition, 16:2, 2001, 317-342.

Linrothe, Rob y Jeff Watt, Demonic Divine. Himalayan Art and Beyond, foreword by Matthieu Ricard Rubin, New York, Museum of Art, 2004.

Nebesky-Wojkowitz, Réne, Oracles and Demons of Tibet. The Cult and Iconography of the Tibetan Protective Deities, Delhi, Book Faith India, 1996.

Rubin, Donald, "Prefacio", en Demonic Divine. Himalayan Art and Beyond, Rob Linrothe y Jeff Watt, foreword by Matthieu Ricard Rubin, New York, Museum of Art, 2004.

Samuel, Geoffrey, Tantric Revisionings. New Understandings of Tibetan Buddhism and Indian Religion, Delhi, Motilal Banarsidass Publishers, 2005.

Platón, Diálogos socráticos, México, WM Jackson, 1974.

Zhamber, Gyaltsho, "Bab Sgrung: Tibetan Epic Singers”, Oral Tradition, 16:1, 2001, 280-293. 